\title{
INTRODUCCIÓN: LA LEYENDA NEGRA EN EL CRISOL DE LA COMEDIA
}

\author{
Yolanda Rodríguez PÉrez \\ (Universiteit van Amsterdam) \\ AnTonio SÁnchez JimÉnEZ \\ (Université de Neuchâtel)
}

La Leyenda Negra parece ejercer una innegable fascinación no solo entre especialistas que estudian la historia de la Monarquía Hispánica y su proyección y percepción internacional, sino también entre un público más amplio, como atestiguan publicaciones recientes sobre el tema (Villaverde Rico y Castilla Urbano 2016) hasta el punto de que resulte común encontrar vestigios de la leyenda en casi cualquier referencia de nuestra época a hechos históricos como la conquista y colonización de América, a instituciones como la Inquisición o a figuras como Felipe II, que aparecen teñidos de un matiz siniestro en películas o referencias de pasada en obras divulgativas. Es más, la perdurabilidad de la Leyenda Negra se materializa en contextos que a primera vista podrían sorprender, como es el de la pasada campaña electoral a la presidencia de los Estados Unidos, y en particular en referencia al programa político de Donald Trump. ${ }^{1}$ Comentándolo, un famoso diario nacional publicó una carta del mencionado Felipe II quien, en una intervención espectral, aconseja al político norteamericano en cuestiones de política interior y exterior, represión de minorías étnicas y religiosas, y otros aspectos útiles para un digno dirigente de imperio de tal magnitud y poder. El autor de la ficticia epístola, un escritor de origen chileno y residente en los Estados Unidos, no solo ofrece una

1 <http://elpais.com/elpais/2016/02/05/opinion/1454670223_017729.html> (artículo de Ariel Dorfman, publicado el 20 de febrero de 2016, última vez consultado el 25 de abril de 2016). 
crítica acerada y satírica de la ideología de Trump, sino que lo hace, $\mathrm{y}$ esto es lo que nos interesa, con una argumentación que aprovecha estereotipos de larga duración sobre la España del Siglo de Oro, y en particular sobre Felipe II, uno de los ejes esenciales alrededor de los que se articula la Leyenda Negra y que en la carta aparece como paradigma de gobernante siniestro, opresivo y fanático. La carta, escrita por un autor literario, ejemplifica una vez más la importancia de la literatura para la formación y la consolidación pública de ideas y de imágenes supuestamente históricas que reflejan preocupaciones e intereses de un determinado momento histórico, en este caso el nuestro. En la época moderna, la literatura, y géneros en particular de gran alcance público como el teatro, tenían obviamente una función similar a la de la carta que acabamos de comentar. Es por ello que hemos decidido dedicar este volumen a estudiarlo.

La Leyenda Negra en el crisol de la comedia. El teatro del Siglo de Oro frente a los estereotipos antibispánicos es el segundo panel de un díptico que estudia la Leyenda Negra como forma de diálogo cultural en la época moderna. El libro precedente, España ante sus críticos: las claves de la Leyenda Negra (Rodríguez Pérez, Sánchez Jiménez y Den Boer 2015), se propuso como objetivo corregir la impresión de que los gobernantes e intelectuales españoles del Siglo de Oro adoptaron un desdeñoso y arrogante silencio ante las acusaciones de la Leyenda $\mathrm{Ne}-$ gra, entendiendo bajo este término el sistema de imágenes que utilizó y difundió la propaganda antihispánica, principalmente la de algunos de los enemigos de la Monarquía Hispánica del momento: holandeses, ingleses y protestantes alemanes. El foco de este primer estudio radicó principalmente en las obras de carácter histórico que contribuyeron a forjar la Leyenda Negra desde su inicio y que ayudaron a extenderla y a hacerla perdurar geográfica y cronológicamente. Por su parte, la intención del presente volumen, La Leyenda Negra en el crisol de la comedia, es dar una idea del dinamismo del discurso narrativo de la Leyenda Negra en el campo literario, en particular el del teatro del Siglo de Oro, periodo de mayor esplendor de la leyenda. No obstante esta focalización genérica y temporal, para mostrar la continuidad histórica del fenómeno y para rastrear el Nachleben de ciertas imágenes y conceptos auriseculares, también extenderemos nuestros límites cronológicos más allá de este periodo histórico.

Son varios los ejes o líneas temáticas alrededor de los que toma forma este libro. En primer lugar, los artículos recogidos ilustran el obvio conocimiento que tenían los dramaturgos áureos acerca del dis- 
curso de la Leyenda Negra y del sistema de argumentación que insistentemente esgrimían los enemigos de la Monarquía Hispánica. En contra de la opinión mantenida por algunos estudiosos, es evidente que autores como Lope de Vega, Vélez de Guevara o Rojas Zorrilla eran plenamente conscientes de la argumentación política de los enemigos del momento y de la existencia de una acerada crítica foránea hacia España, crítica a la que reaccionaron de distintas maneras. En el caso del Fénix, el consciente proceso de negociación y respuesta a ciertas imágenes antihispánicas está ya presente en su obra dramática y poética desde finales del siglo xvi, aunque quizá sean estas famosas y posteriores palabras en la «Epístola al reverendísimo señor don fray Plácido de Tosantos», en La Circe (1624), las que plasman por antonomasia su imperiosa necesidad de contestación:

Y veo de qué suerte nos agravia

la extraña pluma, la parcial malicia,

la historia cautelosa cuanto sabia;

y tan atropellada la justicia

por los historiadores extranjeros,

por pasión, por envidia y por codicia

(Vega Carpio 2003: 633, vv. 208-213).

Esta consciente indignación nos recuerda a la de su amigo Francisco de Quevedo y su laus Hispaniae, la emblemática España defendida (1609-1612), que recogía en forma de un tratado polémico muchos de los mecanismos de defensa que autores como Lope utilizaban en las tablas. Al estudiar esos textos dramáticos la comedia áurea se revela como el medio por excelencia para reelaborar y recrear determinados episodios de la historia nacional y para forjar y matizar paulatinamente ciertas interpretaciones de la misma. El tópico de la relación entre historia y ficción, y del equilibrio entre verdad y exactitud en obras de temática histórica es obviamente asunto inevitable en un libro con esta temática. Por ello, varios autores se detienen a examinar determinados acontecimientos históricos y en estudiar cómo se fueron convirtiendo en objeto literario y canónico; pensemos por ejemplo en el saco de Amberes de 1576.

Otro importante eje temático respecto a las formas de respuesta gira alrededor de la importancia de distinguir entre la existencia de una crítica autóctona, inherente a la gestación y posterior difusión de la leyenda, por un lado, y la Leyenda Negra de acuñación propiamente foránea, por otro. La Brevisima relación de Las Casas no 
es obviamente equiparable a la Apología de Guillermo de Orange, ni en su origen ni en su finalidad. Sin embargo, los dramaturgos áureos eran tanto capaces de integrar en sus obras ecos críticos que dejaban adivinar la perspectiva del otro, como también quejas que procedían de una perspectiva interna y «nacional» como la lascasiana. Y resulta obvio que la Leyenda Negra fue también claramente susceptible a negociaciones y alteraciones dentro del contexto hispánico. De hecho, sabemos que en el marco no-literario de la época moderna existió una sólida tradición de autocrítica hispana articulada por excelencia en la producción de los arbitristas, línea que según los estudiosos llega a perdurar hasta el discurso de los regeneracionistas novecentistas. Se trata de un discurso que a su vez alimentará el ideario de Julián Juderías, hijo de su tiempo, y que inspiraría su estudio emblemático sobre la Leyenda Negra de 1914.

Esencial para interpretar tanto el fenómeno de difusión y perpetuación de la Leyenda Negra como el proceso de respuesta hispánica es ser consciente de la importancia de las estrategias de reescritura y de manipulación que emplearon los escritores tanto en el proceso de creación literaria, como en un campo que contribuyó definitivamente a la construcción de la leyenda: el de la traducción. Ya en España ante sus críticos apuntamos la importancia de los flujos de traducción en conflictos de poder e ideología, como fue el caso de las traducciones de textos canónicos como las ya mencionadas Brevísima de Bartolomé de Las Casas y la Apología de Guillermo de Orange, pero también de otras obras menos estudiadas como la Monarquía Hispánica de Campanella. Estas traducciones son ejemplo de las posibles estrategias disponibles y cristalizan, en palabras de Peter Burke, la idea de «conspiracy of translation» (Burke 2007: 16), marbete que implica cómo la traducción, y la selección de textos a traducir de una determinada cultura, contribuyen a reforzar imágenes y prejuicios ya existentes sobre ese grupo en la cultura de recepción. Estas estrategias siguen vigentes hasta hoy en día, como muestran dos de las contribuciones del volumen, que analizan ejemplos que van desde el siglo xIx hasta el XxI.

El último eje o línea temática pretende recalcar el importante vínculo existente entre el desarrollo de los cánones literarios e históricos nacionales en el siglo xix y del hispanismo como disciplina (sobre todo extranjera), y la formación del concepto «Leyenda Negra» a finales de ese siglo. Como acertadamente comentó el gran conocedor de la Leyenda Negra, Ricardo García Cárcel: «Ciertamente las raíces del hispanismo son de muy amplio espectro. Hay que situarlas en la 
Leyenda Negra respecto a España» (2013: 73). La visión histórica distorsionada de historiadores y literatos extranjeros determinó su forma de interpretar y valorar la producción de los españoles, no ya solo literaria, sino artística en general, como revela uno de los autores de este libro en el contexto musical. Esta distorsión continúa hasta hoy en día por ejemplo en el mundo norteamericano, afectando también incluso a aquellos estadounidenses de raíces hispánicas.

El libro se abre con un artículo de la mano de Bernardo J. García García, que contextualiza la idea de diálogo cultural en el marco de la Leyenda Negra, base de las investigaciones aquí recogidas. Aunque con frecuencia se ha argüido la falta de reacción hispánica a la acerada crítica foránea, sabemos que esta se canalizó a través de vías más sutiles que los panfletos, como fueron los libros, especialmente los de carácter teológico, político y hagiográfico. En los Países Bajos, ejemplo por excelencia de la espiral de odio hispánico, aunque en principio podría parecer que los españoles no respondían a las campañas propagandísticas locales, las estrategias de comunicación eran, de hecho, más de carácter oral que escrito: sermones, proclamaciones, procesiones y todo tipo de formas efímeras de expresión. Para estudiar el fenómeno, Bernardo J. García García se centra en una de estas formas efímeras, las entradas y las celebraciones públicas, y en una forma literaria esencial para perpetuar la memoria dinástica, los elogios. Estas fuentes nos dejan ver de manera cristalina cómo durante el periodo de reinado de los archiduques Alberto e Isabel Clara Eugenia se puso en práctica una política de mansedumbre, blandura y clemencia que debía desactivar la terrible imagen antiespañola arraigada por la propaganda rebelde y a la vez propiciar la "pacificación» y fidelidad de los súbditos en esas latitudes. Esta política se erigía como una antítesis persuasiva frente a la «furia» y la «crueldad» de la nación española y frente a la «ira regis» y «tiranía» vinculada a la figura de Felipe II. Según la nueva propaganda, sus sucesores, Felipe III y los archiduques en los Países Bajos, se presentan como «mansos», clementes, pacíficos, proclives al perdón y la indulgencia de sus súbditos arrepentidos. Episodios del pasado reciente que llegarían a convertirse en canónicos, como la tiranía de Alba, se veían cuestionados en las representaciones alegóricas en arcos triunfales, esculturas efímeras y retablos: las encadenadas Diecisiete Provincias, arrodilladas ante el tiránico gobernante, se ven substituidas por imágenes de armonía y de clemencia absoluta. En lugar de crueles y pérfidos leopardos, los gobernantes españoles son la imagen de la clemencia y el sacrificio: son piadosos pelícanos capaces de ali- 
mentar con sus propias entrañas a esos «descarriados hijos naturales» que son los habitantes de los Países Bajos.

Esta práctica de reacción y esta obvia conciencia de un discurso crítico antihispánico se filtró igualmente en la literatura española de la época, como atestigua este libro. Uno de los episodios más emblemáticos de la Leyenda Negra durante las Guerras de Flandes, recogido y reelaborado en múltiples contextos, tanto textuales como visuales, es probablemente el dramático saco de Amberes en 1576, por el que, según fuentes protestantes, perecieron más de 8.000 personas. El saco se conocería en la época como «la Furia Española» y ejemplificaría la innata crueldad y violencia sin freno de los soldados y (pars pro toto) de todos los españoles. El episodio gozó de gran difusión y encontró su reflejo tanto en la escena española como en la neerlandesa e inglesa. En su contribución a nuestro volumen, Raymond Fagel se detiene ante la cuestión de la causa y responsabilidad concreta del saqueo, combinando el análisis de fuentes literarias e históricas, como crónicas y correspondencia. ¿Fue el saco el resultado de esa violencia y crueldad innata atribuida a los soldados españoles o la consecuencia de una sopesada decisión militar tomada por los mandos y en línea con las prácticas de guerra de la época? El papel de un grupo de amotinados, presentes también en las obras teatrales, complica la interpretación del saco, que es presentado en clave distinta en las distintas tradiciones históricas nacionales. Comparando el famoso anónimo A Larum for London, de gran importancia para el desarrollo de la Leyenda Negra en Inglaterra, y El saco de Amberes de Rojas Zorrilla, el autor demuestra cómo estas comedias se hacen eco de la Leyenda Negra, ofreciendo una interpretación de la premeditación o no de las acciones españolas y también del papel de una figura histórica esencial como Sancho Dávila, castellano de Amberes, y de los grupos particulares envueltos en el estallido de esa inusitada violencia.

En su contribución, Juan Manuel Escudero Baztán se detiene en la cuestión de la reescritura correctiva de la historia en destacados dramaturgos áureos como Lope de Vega y Calderón de la Barca, problematizando la consciente intencionalidad de contrapropaganda por su parte. El autor deja ver cómo Lope de Vega conocía sin duda los «entresijos de la Leyenda Negra» y cómo la vincula con un reforzamiento de la imagen del miles hispanicus, creando una mitografía nueva centrada en un caso particular en la figura de don Lope de Figueroa. En las comedias bélicas del Siglo de Oro el soldado español aparece definido por su virtus militar y por su «porfía», sinónimo de valor, sa- 
crificio y obstinación (concepto esencial en el contexto bélico como ha señalado acertadamente Antonio Cortijo Ocaña [2013]). Este soldado es el contrapunto a críticas sobre la cruenta actuación militar hispánica. Encontramos esta mitografía no solo en las conocidas comedias lopescas del «ciclo de Flandes» como Los españoles en Flandes, El asalto de Mastrique o Pobreza no es vileza, sino también en otras como El cerco del Peñón de Vélez, de Vélez de Guevara. Escudero Baztán matiza cómo en su opinión la intencionalidad de contrapropaganda se va diluyendo en dramaturgos posteriores como Calderón de la Barca. El autor, además, no está de acuerdo con interpretaciones en clave subversiva de dramas como Amar después de la muerte, al considerar que el dramaturgo se encontraba inmerso en la corriente de opinión revisionista de la época. Escudero Baztán acude de hecho al término de «leyenda blanda» para definir los ecos de respuesta a la Leyenda Negra que encontramos en ciertas comedias áureas, apuntando con certeza que no se puede hablar de una respuesta orgánica por parte del Estado, organizada y orquestada desde arriba contra críticas foráneas, pero admitiendo, sin embargo, que los ecos de respuesta están claramente presentes.

En su artículo, Antonio Sánchez Jiménez problematiza la distinción entre una corriente de crítica autóctona de las acciones de los españoles y de la Monarquía Hispánica por un lado y, de una Leyenda Negra de origen y desarrollo foráneo, por otro. Como comentó Ricardo García Cárcel, parte del germen de la Leyenda Negra se encuentra en los escritos de autores hispánicos como Bartolomé de Las Casas, González Montano y Antonio Pérez. Lope de Vega, conocedor de la Leyenda Negra y activo refutador de la misma, juega en dos de sus comedias de original manera con la tendenciosa materia americana: en El Nuevo Mundo descubierto por Cristóbal Colón (c. 1598-1603), pero también en una comedia de temática canaria que es de hecho utilizada analógicamente para dramatizar la materia americana. Se trata de Los guanches de Tenerife (c. 1604-1606), obra que dramatiza las expediciones de conquista a dicha isla. Analizando los estereotipos nacionales que Lope utiliza en ambas obras, Sánchez Jiménez nos muestra cómo el Fénix utilizó sus comedias para reescribir episodios problemáticos de la historia reciente. Estos episodios, como la conquista de América, reverberan en las comedias tratadas al reflejar tanto elementos celebratorios de la conquista, como intentos de conjurar el sentimiento de culpa que causaron. En el caso de Los guanches de Tenerife, Lope refuta la acusación de codicia que pesaba sobre los conquistadores de 
la isla al insistir en la pobreza de los guanches y en el impulso divino de los españoles. De hecho, es una línea que sigue años más tarde Calderón de la Barca en su Aurora de Copacabana, que intentará refutar la Leyenda Negra siguiendo el modelo lopesco de enfatizar la misión evangélica de los conquistadores. En todo caso, hay un elemento en la reescritura lopesca de la conquista de Tenerife que resulta esencial para mostrar que el Fénix conocía las acusaciones foráneas y no se limitaba a seguir las críticas de Las Casas y sus seguidores: la incorporación en la obra del elemento de la soberbia hispánica, uno de los etnotipos más populares de la Leyenda Negra vinculados con los españoles, pero que no formaba parte del discurso lascasiano.

En el marco de la anteriormente mencionada y consciente reacción lopesca a la Leyenda Negra se enmarca la contribución de Leonor Álvarez Francés, quien ilustra la manera sistemática en que el Fénix se dedicó a contestar a la Leyenda Negra en su teatro. Centrándose en un análisis de una de las más emblemáticas comedias del «ciclo de Flandes», Los españoles en Flandes, la autora cuestiona y armoniza interpretaciones encontradas de la famosa comedia. Así, Álvarez Francés demuestra que el carácter subversivo de determinados elementos presentes en la misma no es incompatible con otros de triunfalismo nacional si se analizan también desde una perspectiva imagológica que vincule las imágenes hispánicas con las del enemigo holandés. El conocimiento que tenía Lope del conflicto en Flandes, de su carácter de guerra civil y de la visión de los españoles en consonancia con la Leyenda Negra es innegable si vemos cómo verbaliza en boca flamenca los cuatro aspectos más característicos (y negativos) de la presencia española en Flandes: codicia, soberbia, opresión y crueldad. Aunque en opinión de Álvarez Francés hay innegables cabos sueltos en el sistema de respuesta a la Leyenda Negra y en la construcción idealizada del español leal y sacrificado, la autora nos muestra las variadas estrategias de negación o refuerzo de esas imágenes que esgrime el famoso dramaturgo, y además bosqueja el proceso de contestación de la Leyenda Negra pars pro toto en referencia a la milicia española o al español soberbio. Para ello contrasta los resultados de su análisis de Los españoles en Flandes con otra comedia lopesca de materia histórica extranjera compuesta por el Fénix alrededor de las mismas fechas: $L a$ contienda de García de Paredes.

El artículo de Alexander Samson, por su parte, explica las distintas maneras en que la comedia aurisecular aprovechaba la materia histórica, concentrándose en concreto en el papel que desempeñaban estas 
representaciones en la creación de una conciencia pública de asuntos políticos y matizando su interpretación exclusiva como vehículos de la propaganda e idealización de la soldadesca española. Una comedia como Los amotinados de Flandes, de Luis Vélez de Guevara, centrada en el tema de los motines, se representó en los corrales tras la tregua de los Doce Años, en 1621, periodo en el que los motines ya no estaban más a la orden del día. ¿Por qué, pues, elegir esta temática? Samson arguye que no podemos considerar Los amotinados de Flandes como un mero «blanqueamiento de la historia», con su romantización de la soldadesca española y la omisión de detalles que pudieran crear una imagen más siniestra sobre el motín. Esta comedia, y muchas otras, son ejemplos de intervención en debates políticos vigentes. Al centrar una obra en los motines, el autor avisaba a los partidarios de la línea dura de las realidades de las largas campañas en Flandes y subrayaba lo imprescindible de movilizar los recursos necesarios para llevar a cabo una guerra y evitar la pérdida de honor y fama que resulta de motines constantes y mala gestión. Esta comedia presenta de este modo una forma sutil de respuesta a la Leyenda Negra, aunque no refutando lo que dice el enemigo extranjero, ya que no se le otorga casi ni voz ni espacio y se le presenta sumido en una guerra civil.

La siguiente contribución del volumen, de Yolanda Rodríguez Pérez, nos ofrece un ejemplo de una inesperada evolución en el discurso teatral de la Leyenda Negra en la época moderna: un caso de reescritura de una obra teatral sobre uno de los principales protagonistas de la leyenda, el príncipe don Carlos, pero, en clave acorde a la Leyenda Negra. Los ecos de crítica autóctona que caracterizan la narrativa de la Leyenda Negra desde sus primeras fases y que aparecen analizados en varias de las contribuciones de este libro continúan, pues, perdurando a lo largo de los siglos también en el contexto literario, en función de nuevas necesidades históricas. Este es el caso de la refundición de $E l$ príncipe don Carlos de José de Cañizares, representada en Madrid en 1708. La obra, basada en la comedia homónima de Jiménez de Enciso (compuesta antes de 1634), altera la apologética trama original y sustituye su final triunfalista de unión armónica entre padre e hijo por otro con la dramática muerte del desdichado príncipe y con un papel muy sospechoso para el rey Felipe. De hecho, en la versión de Cañizares, se vinculan al rey prudente las muertes no solo de don Carlos, sino también del noble flamenco Montigny. Varias adiciones en esta versión enfatizan la culpabilidad y el tenebrismo de la figura del rey Felipe acorde a la Leyenda Negra foránea tan popularizada tras la famosa no- 
vela histórica del abad de Saint-Real Dom Carlos. El contexto político de principios del xviII, en plena Guerra de Sucesión, con un nuevo rey Felipe $\mathrm{V}$ que deseaba distanciarse de la anterior dinastía Habsburgo y perfilarse como monarca borbónico, es esencial para intentar interpretar esta curiosa reinversión leyendanegrista de este dramático episodio de la historia de España.

El reflejo de la Leyenda Negra no solo es perceptible en la temática y en la caracterización de figuras hispánicas y de enemigos y aliados foráneos sobre las tablas. Lucía Díaz Marroquín trata en su contribución un aspecto más sutil pero igualmente revelador del funcionamiento e instrumentalización de estereotipos nacionales pertenecientes a la Leyenda Negra en el contexto teatral: el de la música. El teatro español del siglo XviI está repleto de resonancias vocales y musicales que también se hacen eco de imágenes de distinciones nacionales en boga en la época. La autora comienza con una útil e interesante introducción sobre la caracterización de personajes y de sus acciones en $D e$ inventione de Cicerón, según el que los personis attributa eran caracterizados por su natura y por el decoro correspondiente a su nación. Como cabría esperar, las teorías humorales se combinan también en estas taxonomías caracterológicas y nacionales que llegaron a afectar las ideas musicales del momento. Y es que en el siglo xvir los distintos territorios europeos mostraban claras divergencias respecto a la interpretación y la técnica vocal. En ese contexto, Díaz Marroquín nos muestra cómo las voces hispanas, con un claro influjo árabe, fueron interpretadas en clave étnica en consonancia con los estereotipos y prejuicios de la Leyenda Negra. Al énfasis en la falta de pureza racial hispánica, fruto de mezcla con judíos y musulmanes, se añadían lecturas de tenebrismo en las voces hispánicas, reflejo de su temperamento atrabiliario. Así, la autora nos hace referencia a los comentarios en esta línea del diplomático y literato holandés Constantijn Huygens. Estos estereotipos vocales étnicos «ennegrecidos» son objeto de llamativa continuidad histórica y los encontramos en pleno apogeo en los juicios respecto al tenor español Manuel del Pópulo García a principios del siglo XIX y posteriormente en la famosa ópera de Verdi, esencial en la perpetuación de la Leyenda Negra y del mito de don Carlos en particular.

Un campo que se revela de gran importancia para la (re)construcción de imágenes nacionales y de estereotipos culturales es el de la traducción. Las tres últimas contribuciones integran en su argumentación esta línea traductológica. Gracias a figuras como Peter Burke, 
hemos sido testigos los últimos años de un «giro cultural» que postula la colaboración entre disciplinas como la historia, la literatura y la traducción. A esta iniciativa se une la vinculación con el campo de la imagología, el estudio de representaciones literarias nacionales ${ }^{2}$. En este marco, Javier García Albero presta atención a este reciente desideratum al concentrarse en la traducción de varias obras canónicas en el desarrollo de la Leyenda Negra en el contexto alemán. Estas obras han resultado definitivas para determinar el imaginario europeo posterior respecto a la Leyenda Negra y su reflejo de España y los españoles. Partiendo de la tradición de «manipulación de la literatura», García Albero se concentra en dos conceptos claves en la interpretación traductológica desde una perspectiva ideológica: la reescritura y la manipulación del texto original en la literatura de llegada. Sin ceñirse a comparaciones filológicas tradicionales, y para determinar el alcance de manipulación del original, el autor combina el análisis del texto con el de los paratextos y el contexto del momento. En el caso de las obras analizadas, las Artes inquisitoriales de Reinaldo González Montano, la Historia del Mondo Nuovo de Girolamo Benzoni y la famosa y controvertida Brevísima relación de la destruición de las Indias del padre Bartolomé de Las Casas, es importante apuntar que el contenido de estas traducciones se vio reforzado por la adición de grabados antihispánicos como los famosos de Theodor de Bry. Aunque García Albero resalta la tendenciosidad de la versión alemana de la Brevísima relación, que claramente carga las tintas contra los españoles e intenta borrar críticas del protestantismo o de las acciones de los alemanes en América, el autor comenta que en la traducción alemana de Benzoni, publicada por De Bry y acompañada de un prólogo de su propia mano, el grabador flamenco matiza la crueldad de los españoles, añadiendo que había más naciones que incurrieron en violencia y crueldad. Pero estos ecos de puntualización han sido mayoritariamente obviados en el contexto de difusión y uso de la Leyenda Negra.

Con las dos últimas contribuciones del libro nos adentramos en el siglo xix y llegamos hasta nuestros días, ejemplificando de este modo la perdurabilidad de ciertas imágenes hispánicas vinculadas con la Leyenda Negra. Julio Vélez Sainz sigue la anteriormente apuntada línea traductológica en su artículo sobre la History of Spanish Literature del norteamericano George Ticknor y su traducción al español por Pascual de Gayangos y Enrique de Vedia. Su análisis nos ofrece un muy

2 Véase Van Doorselaer, Flynn y Leerssen (2016). 
revelador ejemplo de cómo los prejuicios hispanófobos se filtraron en historias decimonónicas de la literatura española, demostrando la mencionada vinculación entre el hispanismo y la hispanofobia y cómo, en el caso del legado del Siglo de Oro, estos autores intentan encontrar un equilibrio entre la «noción de limpieza» áurea y los tenebrosos ecos de la Leyenda Negra. Además, la supuesta existencia de un bomo bispanicus con ciertas características innatas y estables desde la edad moderna enturbiaba ese intento de equilibrio. En la obra de Ticknor, uno de los grandes hispanistas de su tiempo, encontramos tanto estos ecos como visiones exóticas y románticas del «otro» español, pero, pese a ello, el suyo es uno de los primeros intentos serios de historiar la literatura española con rigor y distancia. Particularmente interesante es cómo Vélez Sainz analiza la manera en que en la traducción española de De Gayangos y De Vedia los autores introducen el marbete «Siglo de Oro» en lo que podríamos definir como una reacción nacionalista que intentar dar más lustre a ese periodo literario de lo que hace el norteamericano en su original. Este marchamo se acabaría de consagrar a lo largo del siglo xix, en un proceso de consolidación que refleja a su vez un complejo fenómeno de construcción nacional.

Concluimos este libro con una contribución de Barbara Fuchs donde se hace palpable la línea de longue durée de la Leyenda Negra, al tratar ejemplos que llegan al siglo xxi y que integran el proceso de traducción como instrumento esencial en la matización o continuación de imágenes y estereotipos nacionales a través del tiempo. Punto de partida de Fuchs, en línea con Vélez Sainz, es la existencia de un canon literario anglosajón respecto a la literatura española forjado en el siglo XIX y marcado por los prejuicios nacionales y por la beligerancia hacia lo hispánico. El estudio de la literatura española parte de una idea inicial de «diferencia» o contraste entre países que niega el carácter transnacional de, por ejemplo, el drama en el Siglo de Oro al negar posibles influencias hispánicas en el teatro inglés. Fuchs hace patente cómo hispanistas decimonónicos como Charles Dibdin reflejan esta tensión interna en su apreciación literaria de la producción española, pero también apunta que no hemos de olvidar que los propios españoles también contribuyeron a la Leyenda Negra, manipulando esa diferencia. En su intento de ofrecer visiones alternativas de España y del capital cultural hispánico en el contexto norteamericano, la autora nos relata el intento de un grupo dentro de la UCLA de desarticular un canon literario anglosajón que confirma visiones estereotípicas anglo-hispanas de larga duración. Con la iniciativa «Diversificar los 
clásicos» se están llevando a cabo traducciones de obras del Siglo de Oro español que justo retan esos estereotipos de España, por ejemplo respecto a cuestiones de género en el papel de las mujeres protagonistas o de la importancia del honor como elemento definitorio del teatro del Siglo de Oro.

Para los estudiosos de la época moderna y en particular de las (auto)-representaciones hispánicas en sus múltiples formas y fuentes, la «Leyenda Negra» ofrece un extraordinario caudal de imágenes que son objeto de continuidad y discontinuidad histórica. Esta narrativa es además una de las más persistentes en Europa y América respecto al enemigo histórico, pudiéndose afirmar que perdura en múltiples transmutaciones y formas. Algunas curiosas, ya sea con interpretaciones de Felipe II (pars pro toto de la leyenda) como álter ego histórico de Donald Trump en estos momentos, o de Bin Laden en tiempos de George W. Bush. En todo caso, lo notable es el hecho de que hablamos de un prolífico discurso cruzado en la Europa de la época moderna, en el que se enzarzaron no solo intelectuales, sino también aquellos que producían entretenimiento para las capas más amplias de la población. Por último, y volviendo a secundar la idea expuesta en nuestro anterior libro sobre la Leyenda Negra, lo que no hemos de olvidar es que este patente antihispanismo se vio acompañado, en el contexto cultural, por una gran e innegable atracción y admiración hacia España, una fascinación que en ocasiones derivó hacia la hispanofilia.

\section{OBRAS CITADAS}

Burke, Peter y Ronnie Po-Chia Hsia, Cultural Translation in Early Modern Europe, Cambridge, Cambridge University press, 2007.

CoRtijo OcaÑa, Antonio, La porfía: identidad personal y nacional en Lope de Vega, Barcelona, Anthropos, 2013.

Doorslaer, Luc van, Peter Flynn y Joep Leerssen (eds.), Interconnecting Translation and Image Studies, John Benjamins Publishing Companies, Amsterdam, 2016.

García CÁrCel, Ricardo, «Reflexiones sobre la leyenda negra», en Las vecindades de las Monarquías Ibéricas, ed. de J. J. Ruiz Ibáñez, Madrid, Fondo de Cultura Económica, 2013, pp. 43-80.

Rodríguez Pérez, Yolanda, Antonio SÁnchez Jiménez y Harm den Boer (eds.), España ante sus críticos: las claves de la Leyenda Negra, Madrid/Frankfurt a. M., Iberoamericana/Vervuert, 2015. 
22 YOLANDA RODRÍGUEZ PÉREZ / ANTONIO SÁNCHEZ JIMÉNEZ

Vega Carpio, Lope de, La Circe, en Lope de Vega. Poesía, IV, ed. de Antonio Carreño, Madrid, Biblioteca Castro, 2003, pp. 351-747.

Villaverde Rico, María José y Francisco Castilla Urbano, La sombra de La Leyenda Negra, Madrid, Tecnos, 2016. 